\title{
THE SENSE OF ENTRANCE TO A PLACE IN KASHAN HISTORICAL HOUSES
}

\author{
Ahmad DANAEINIA (iD * \\ Faculty of Architecture and Art, University of Kashan, Iran, Kashan
}

Received 28 July 2020; accepted 08 December 2020

\begin{abstract}
The sense of place is like a mental perception of people individuals and the conscious feeling of the environment and the entrance as important signs cause the formation of mental image and the continuity of sense of belonging to the place in people. The character that the entrance takes is an important factor for the connection between inside and outside the building. The research question is what are the criteria for recognizing entrance architecture? And how have these criteria been able to improve the continuity of the sense of belonging to the place in the inhabitants of the historical context of Kashan? In the architecture of Kashan's houses, entrance space as a conceptual element has high importance and reflects the architectural, cultural, and social values. This important element, which is based on behavioral patterns, has lost its identity today and has been reduced scale to a separating outside from inside. Studies show that integration and integrity, the radius of vision, and visual depth are three important indices designed based on them. This research through case study and using Depth map software has examined these characteristics at the entrance of nine historical houses in Kashan. The results show that the design of these entrances has the highest degree of coherence and a maximum radius of view and due to high visual depth have high privacy.
\end{abstract}

Keywords: sense of entrance, place, promotion of dependence, historical houses, Kashan.

\section{Introduction}

The entrance as a sign has special features because in addition to the main function, visually and conceptually, it is the interface between the building and urban space. And it is a criterion for the value and identity of each building's architecture and society, and through it, the identity of the building can be measured. Each person can have a pleasant, undesirable, or neutral sense of place in accordance with their cultural, social, mental, and intellectual characteristics. Sense of place is a psychosomatic phenomenon that is completely influenced by one's perceptions, memories, experiences, and moods, so it will vary from person to person (Ghahari, 2015).

The environment is both physically and socially shaken. Humans create spaces and give them meaning. Humans are interacting with the environment. They have positive and negative effects on the environment and return it to the environment. These spaces and environments affect the human mind and behavior. In addition to physical elements, the environment includes messages, semantic signs, and codes that humans perceive based on their perceptions of the signs and motives of deciphering (Rapaport, 1990).
The general sense that arises in a person after the interpreter's perception and interpretation of the environment is called the sense of place (Falahat \& Noohi, 2012, p. 58). The sense of place is the most important criterion for the semantic quality of architectural space, which ultimately creates harmony between the individual (human) and the environment (architectural space) and better exploitation of the environment and the continuity of its presence. Thus, the sense of place is influenced by the quality of the space and how it is designed, and it has a deep connection with personal values. Relation with location is categorized as biography, spiritual, belief, narrative, material, and dependence.

The entrance of the house plays an important role in promoting the sense of belonging to the place and in a two-way relationship; it both strengthens the characteristics of the neighborhood as an urban place and identifies the architecture of the house as an architectural place.

\section{Sense of place}

The place is where it happens to be (Relph, 2008, p. 5) and as a center of meaning" often focus on the meanings that shape actions or everyday experiences (Wagenaar,

${ }^{\star}$ Corresponding author. E-mail: danaeinia@kashanu.ac.ir 
2011). Place meanings are treated as a social practice that cannot be understood outside of interactional, cultural, and institutional contexts in which they emerge. They are formed through everyday language use and social practice and have important rhetorical relevance (Di Masso et al., 2014). It is also generally accepted that place attachment endures over time (Lewicka, 2011), and slowly changes in intensity or structure with one's length of residence in a given place (Hammitt et al., 2004; Brown \& Raymond, 2007), or waxing and waning over the course of one's connection to a place (Smaldone et al., 2008). Interest in sense of place has grown rapidly in recent years, with the concept extended from leisure and recreation to a wide range of applications and settings (Raymond et al., 2017).

An important part of the perception of beauty, namely the perception of meaning, signs, and symbols, in addition to being of special importance in aesthetic preferences, determine the characteristics of people's relationship with space. Spatial identity as one of the ways of communication between human beings and space through Culture, Historical History, Collective Memories, Type and Nature of Construction Technology, Functions, Signs, Forms, and Urban Symbols and Features Visual and physical are perceived; therefore, it is theoretically related to the aesthetic aspects of a place.

Proshansky believes that place identity is a subset of identity. Man not only records the environment in his mind but also expands his feelings and ideas about it and communicates with the environment in the same way that his identity considers it important (Proshansky, 1978).

Spatial identity stems from individual and collective values and, expands and changes over time (Relph, 2009). In analyzing the relationship between human activities and place, habitation establishes a meaningful relationship between humans and the environment and in this regard, the two factors of space and sense of belonging, which are derived from the individual and collective memories of residents, are important factors and variables in the formation of this meaningful relationship. The first factor is related to the recognition of space and its physical functions and efficiency and the second factor is the emotional performance of the environment, which is interpreted as the feeling of belonging to the place (Norberg-Schulz, 1981, p. 34).

The relationship between humans and place is interactive, and the notion of place is not only physical but also psychological and interactive. Altman believes that some spaces have such a strong spirit that they have a similar effect on different people (Altman \& Low, 1992, p. 123). The entrance to the houses is no exception. Despite their physical similarities, they create different psychological effects for each place.

In another study, a four-level assessment model has been proposed for the sense of place (Shamai, 1991). According to the results of this study, increasing the level of Behavioral desire in society is directly related to increasing the level of sense of belonging to the place.

The environment consists of a set of behavior patterns that are interconnected and have common seasons. The main elements of these behavioral camps are the pattern of behavior index and the physical environment.

Behavioral desire in society is directly related to increasing the level of sense of belonging to the place.

Rapaport considers the environment to be the product of meaningful communication. In his view, the environment may be seen as a series of connections between objects and objects, objects, and people and people and people. These communications are regular. And they have a pattern and a structure (Rapoport, 1990, p. 34). As an urban designer, Parkinson sees the environment as a result of the interaction between individuals and the physical place, and believes that the built environment is more than just a building. This is the result of a very complex interaction between people and places (Parkinson, 2000, p. 77).

\section{Sense of place from a phenomenological point of view}

The term sense of place is composed of a combination of the sense and place of the word. Sense means the total or total cognition of an object by man, but the word sense in the sense of place is more in the sense of emotion, love, judgment, and the overall experience of a place or its ability to create a particular sense of belonging to individuals. From an environmental psychology perspective, humans need a specific sensory, emotional, and spiritual experience of the living environment. These needs can be met through intimate interaction and a kind of identification with the place where you live (Figure 1).

From the phenomenological point of view, the concept of place sense means the truth and nature of the place, which indicates the importance of the meanings and messages in the place. Meanings that people decipher and understand based on roles, expectations, motivations, and other factors (Rapaport, 1990). Accordingly, the sense of place is a perceptual ability and can combine the powers of sight, hearing, touch, movement, and mobility, purpose, and prediction.

Critical and positivist views, on the other hand, emphasize how human, cultural, and gender differences affect the formation of a sense of place (Messy, 1994, pp. 146157) that this indicates the interaction between individual and collective values, attitudes and sense of place (Falahat, 2006, p. 85; based on Canter, 1971). Another important discussion about the concept of place sense is the various levels of concept that various theorists have pointed out

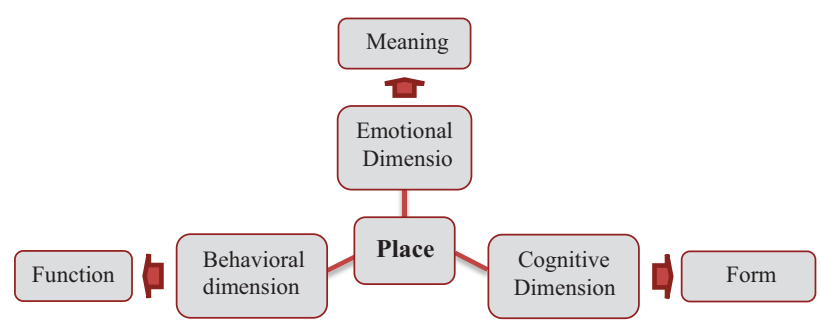

Figure 1. Dimensions of creating place (Hashemzadeh et al., 2013, p. 8) 
Table 1. Different levels of sense of place

\begin{tabular}{|l|c|c|c|}
\hline \multicolumn{4}{|c|}{ The sense of place } \\
\hline \multicolumn{1}{|c|}{ Shamay (1991) } & Crass (2001) & Hyouman (1992) & Gaso (1976) \\
\hline Indifference to place & Absolute placelessness & Unplaced & Surface familiarity with a place \\
\hline Awareness of placement in a location & Relative placelessness & Alienation with place & Normal familiarity with a place \\
\hline Belonging to a place & Alienation with place & Relative place & Deep familiarity with a place \\
\hline Attachment to place & Incoherent rooting & Unconscious rooting & \\
\hline Becoming one with the goals of a place & Rooted cohesive & Ideological rooting & \\
\hline Attend one location & & & \\
\hline Sacrifice for a location & & & \\
\hline
\end{tabular}

in their meanings and interpretations. Table 1 shows the different levels of sense with the place.

Thus, by considering the sense of place as a concept that takes place after understanding the meanings of place and judging about it, we can understand the close connection of this concept with concepts such as the perception of place and meanings of place that reflect the role and special place of place meanings and perception is about forming a sense of place.

\section{The importance of sense of place in improving the quality of architectural space}

With the development of human societies and the emergence of meaning gaps in constructed spaces, the quality of spaces, and the role of perceptual components in shaping different spaces have been considered by environmental designers and planners. Spaces that evoke a sense of belonging and identity followed by peace and joy in the mind of the audience and revive the feeling of presence and being in the place. The sense of place is influenced by the meanings and many psychological-behavioral conventions of society. From the point of view of phenomenologists, the sense of place means the connection of place with the understanding of everyday symbols and activities (Relph, 1976). Individual and collective values affect how the place feels, and the sense of place affects the values, attitudes, and especially the individual and social behavior of people in the place, and people usually participate in social activities according to how they feel (Falahat \& Noohi, 2012, p. 58). This feeling is a factor that turns a space into a place with special emotional and behavioral characteristics for certain people and it supports the cultural concepts of the people and the social relations of the society in a specific place and reminds them of past experiences and achieves identity for individuals.

Phenomenology considers the sense of place through the understanding of everyday symbols and activities. This feeling can be created in a person's living space or space with which he or she is connected, and it can deepen and expand over time (Relph, 1976). Individual and social values influence how a sense of place is perceived, and individuals participate in social activities according to how they perceive the sense of place. The main thing about the place is that people place their activity in a special place, and specialization is one of the most important human activities and experiences. Therefore, the sense of place is not only a factor for the harmony between man and the architectural space but also a factor for creating a sense of calm, security, pleasure, and emotional perception of people.

The entrance of houses is considered as one of the most significant semantic factors in creating mental associations, an effective factor in promoting the sense of place, increasing the sensory and emotional perceptions of the audience and the quality of home architecture.

\section{The meaning and process of perception}

The study of meaning indicates that the audience gives meaning to the work and interprets the work according to its own taste. The birth of a commentator is an excuse for death. The commentator interprets the work with his experiences, goals, and intentions (Norouzitalab, 2006, p. 102). Bourdieu argues that each phenomenon exhibits meaning at both the primary and secondary levels. At the primary level, the main characteristics of the phenomenon, such as color, shapes, and structures, are renewed, and at the secondary level, symbolic meanings are included (Bourdieu, 1977).

Meaning is located within space, and in the first stage it contains the meanings in the human mind and is influenced by social and cultural values and factors, and in the second stage, it is somehow influenced by values because places are formed under the influence of society's values. Therefore, in the field of factors affecting perception, it was classified into three personal factors (man and the meanings in his mind) physical (place, environmental characteristics and meanings in place) and cultural (sociocultural beliefs and values).

\subsection{Place character}

The position of the entrance refers to indicators that are influenced by beliefs, feelings, values, and attitudes of conscious or unconscious behavior, the identity of individuals in relation to one place (Proshansky, 1978, p. 151). Therefore, the position of the place refers to the dimension of the human - location relationship that allows for the emergence and emphasis of identity for individuals. The character of the place in a neighborhood is a reflection of 
the beliefs that one has a residential neighborhood. Assessing and measuring the personality of a place in residential neighborhoods can include judgments about the basic concepts of Breakwell's personality process model, namely difference, continuity, self-esteem, and self-efficacy (Breakwell, 1992). Continuity refers to the desire to maintain identity over time and space and self-esteem here is an expression of the pleasant feeling one has of being assigned to one or another environment (Twigger-Ross \& Uzzell, 1996, p. 209). Therefore, the judgment of individuals to assess and measure the sense of difference, continuity, efficacy, and pleasantness that a person acquires in the environment or through the ratio given to a residential environment can be a good model for assessing the position of the place.

\subsection{Dependence on the place}

Attachment to a place can be a reflection of residents' emotional evaluation of that place. Contrary to some research hypotheses, attachment to space is the only product of social interaction in a neighborhood Numerous studies have shown that emotional attachment to a place can be related to the physical and social environment (Jorgensen \& Stedman, 2001, p. 239; Kyle et al., 2005, p. 156). As some researches have reported that a sense of belonging to a physical environment, even independent of social interactions, is possible (Hidalgo \& Hernandez, 2001, p. 278).

Stokols and Shumaker (1981) suggested that there are two factors that individuals and groups employ to deter-

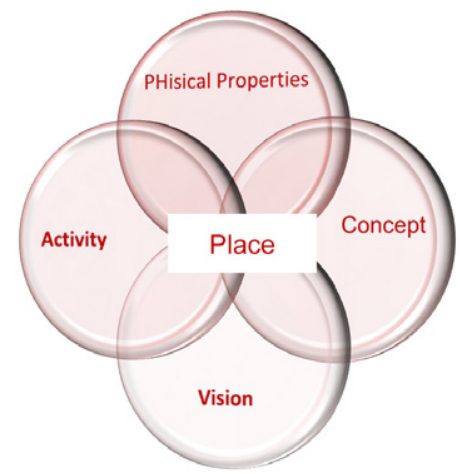

Figure 2. Virtual reality about the nature of the place (Canter, 1971, p. 258) mine place dependency. The first is the quality of the current place and the second is the relative quality of comparable alternatives. Figure 2 shows the virtual reality about the nature of the place.

The most important aspect of Dependence on a place is the spatial values of that place which is formed and continues through the connection between people and the environment. Depending on the place emphasizes how much and with what quality extent a physical environment can provide the capabilities of achieving the behavioral goals of individuals in comparison with possible and available alternatives (Jorgensen \& Stedman, 2001, p. 279). Place identity, place attachment and place dependence can be viewed above all as cognitive, affective and behavior dimensions, respectively (Jorgensen \& Stedman, 2006, p. 321). Therefore, a place can be important and dependent on people because of its functional values (White et al., 2008, p. 87). Over time, places create coherence by recalling events that have taken place in the past and by allowing people to compare the past and the present. In this case, the environment represents a part of one's personal history (Scannell \& Gifford, 2010, p. 5).

\section{Thematic expectations from the entrance}

The entrance is the first place where the characteristics of space, privacy, and publicity and other general features are discovered. In fact, by arranging the entrance of a space (city, a neighborhood, or a building), that space is discovered, identified, and revived by its inhabitants (Alexander et al., 1977, p. 277). The entrance as a place to connect requires special expectations based on the mental image and experiences of the people and exceeds it as an entrance door. Converting indoor and outdoor spaces, creating an event, inviting, convertibility, permeability, and visual connection are some of the expectations expected from the entrance (Mozaffaripour, 2014, p. 20).

To create this event, the openness of the path of vision (radius of vision) and the expansion of visual depth (intimacy) from privacy to the public helps a lot. Therefore, the input character is formed in connection with the environment and the place where it is located and is completed by combining with the inner space.

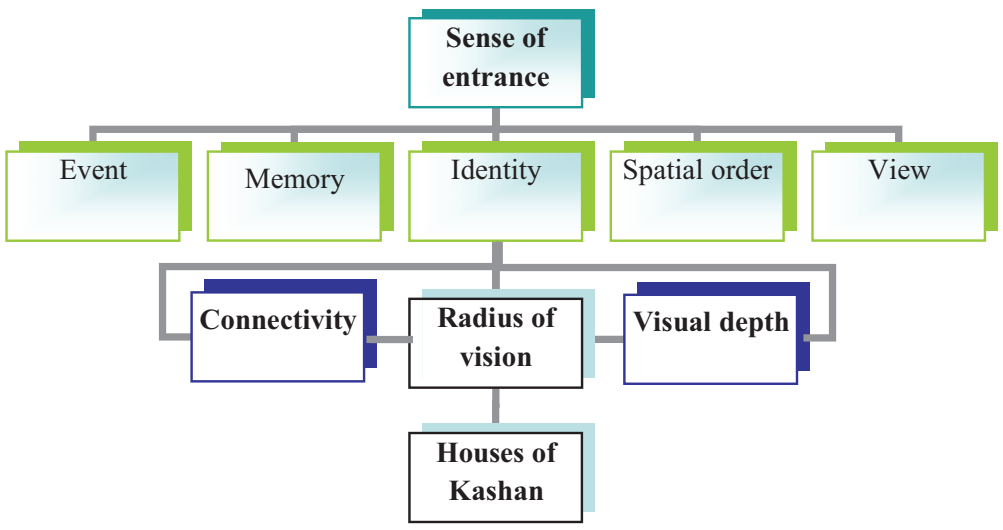

Figure 3. Thematic expectations of entrance 
The entrance, as a sign, has its own characteristics and advantages, because in addition to its main function as a communication space in terms of visual and perception, it is also a space between the building and urban spaces and it has often been a criterion for the value and identity of the architecture and society of any building, especially in cities with continuous and dense context.

The entrance space in Iranian architecture is so important that an important part of the evolution of traditional architecture has been manifested in it. Thus the entrance as an in-between space between inside and outside the house (Sultanzadeh, 1993, p. 170) and the link between the outside and the inside (Mehdipoor et al., 2013, p. 5 (has the highest level of privacy (Tavassoli, 2008, p. 129).

Different places create different mental images of space. Human perceptions, rooted in meaning, are perceived by mentalities and can provide a basis for the creation of senses. Therefore, signs can be considered as an effective factor in promoting the sense of place (Falahat \& Noohi, 2012, p. 18). These signs are formed through the event, Memory, Identity, Spatial order and View in Kashan's houses (Figure 3).

\section{Cognitive components of entrance architecture in the historical context of Kashan}

Entrances are an important factor in the social interactions of the inhabitants of the historical context of Kasha. There are many houses in each alley or dead-end that creates a special privacy for people. Therefore, the entrance is the first place for the formation of social solidarity, which is based on cultural requirements and is an important factor for self-sufficiency and the formation of small communities. Accordingly, the entrance of Kashan houses as a residential territory is considered an important factor for collective protection. This important issue appears in the form of cognitive, behavioral, emotional and functional interactions with mutual understanding, and high social efficiency. This functional combination has created a deep connection between the interior space of the house and the neighborhood (Figure 4).

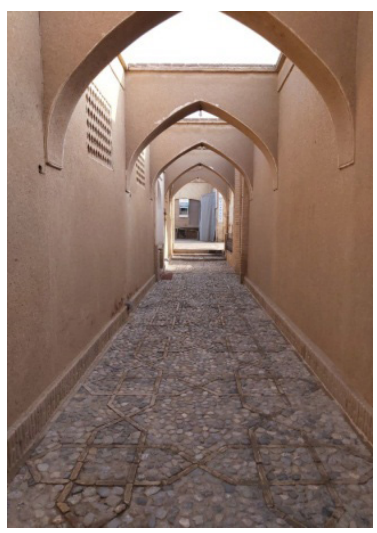

a)

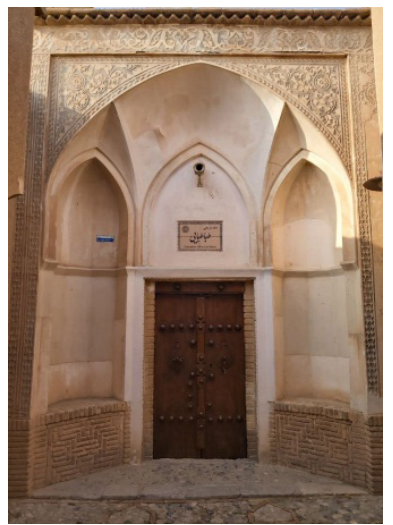

b)
Thus, the input is effective in restoring the individual and social personality of the residents of the neighborhood in Kashan. Residents also ensure the security of the neighborhood by seeing and being seen. Entrance creates a familiar community and promotes the social benefits of individuals. In general, the entrance space in Kashan houses, which should not be considered only as a component-space but should be defined as an important issue of neighborhood architecture, includes the following features:

- Grounds for sustainable development on a small scale.

- The factor of social actions and the context of meaningful connection between man and the environment.

- A place to see and be seen.

- Encourage stay and location.

- Monitoring, control, and security agent.

- Filling the gap between the scale of the house and the neighborhood.

- Background for forming small social groups and face to face.

- A factor in maintaining social balance and unity in the neighborhood.

\section{Method}

\subsection{Case studies}

Kashan is one of the historical and original cities in the central plateau of Iran and the architecture of its houses among the historical cities of Iran has a special privilege. Kashan has more than a thousand historical houses. Tourists who visit the city often want to visit its historic houses. The variety of historical houses in this city is so great that it is called the city of historical houses. The entrance to Kashan's houses is very beautiful and amazing, but unfortunately, due to numerous street protests in the city in recent decades, it has been seriously damaged and in some cases renovated or reconstructed.

\subsection{Instrument}

The research is based on qualitative methods and based on field observations and analysis. The data presented in

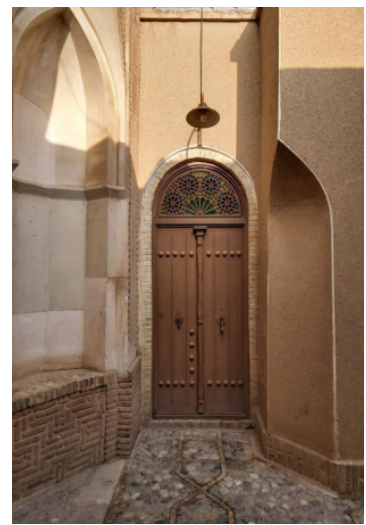

c)

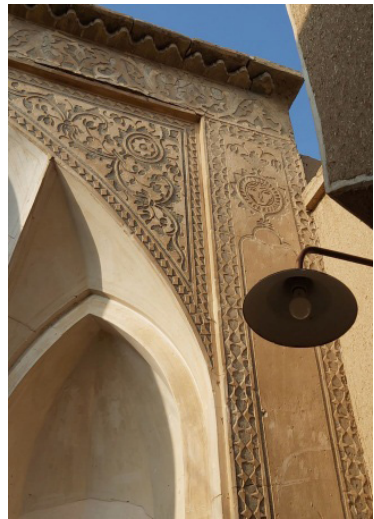

d)
Figure 4. Different expectations of entrance in Tabatabai's house in Kashan (19th century): a - home access hierarchy; $b$ - main entrance; $c$ - subsidiary entrance and d - details 
this study was gathered from nine historical buildings in Kashan. First, based on library studies, the components affecting the entrance architecture have been identified and then through field studies, and then the characteristics of integration, radius of vision and visual depth (intimacy) have been investigated with the help of Depth map software. Space syntax is a set of theories and techniques related to spatial configuration analysis. In this method, spaces can be divided into components and analyzed as selected networks and then introduced as maps and diagrams that describe the relative relationship and integrity of those spaces. In this research the samples were selected based on cluster classification and considering an equal opportunity for all neighborhoods and considering the historical originality of the building.

\subsection{Sample analysis}

Figure 5 shows the entrance view of the studied houses. In field studies, to get acquainted with the entrance space, the entrance position to the passage, the hierarchy of access to the house, the full and empty volume, and the geometry of the house have been studied.

Form and volume, visual quality, ratios and proportions in entrance design, prolific decorations, the possibility of presence and interaction, thought hierarchy and centralized geometry based on cultural, social and climatic characteristics of Kashan city have been introduced in the entrance architecture (Figure 5).

Figure 6 emphasizes the important and functional role of the input as the connection point between the outer and inner space and its role in the spatial arrangement.

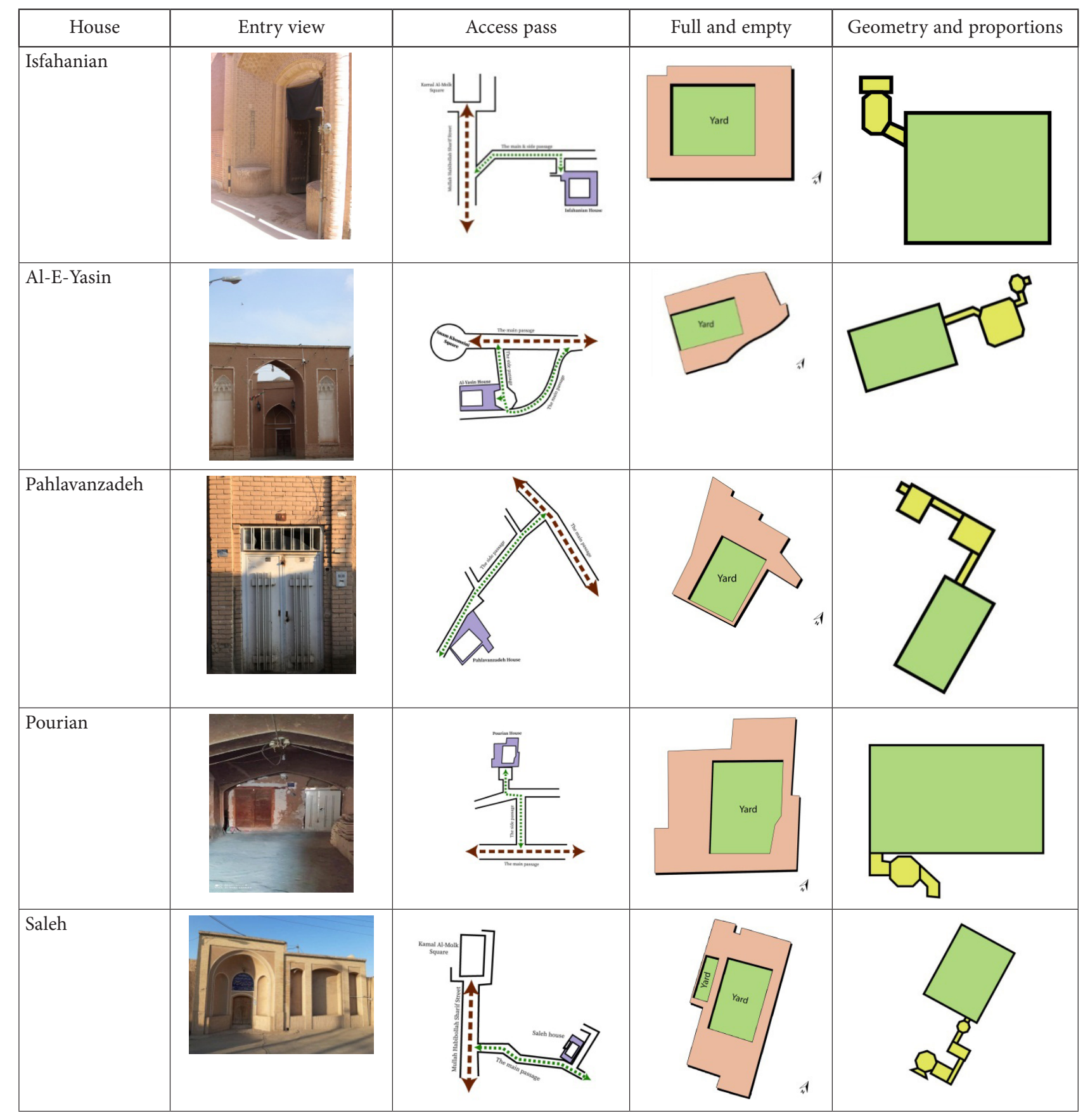




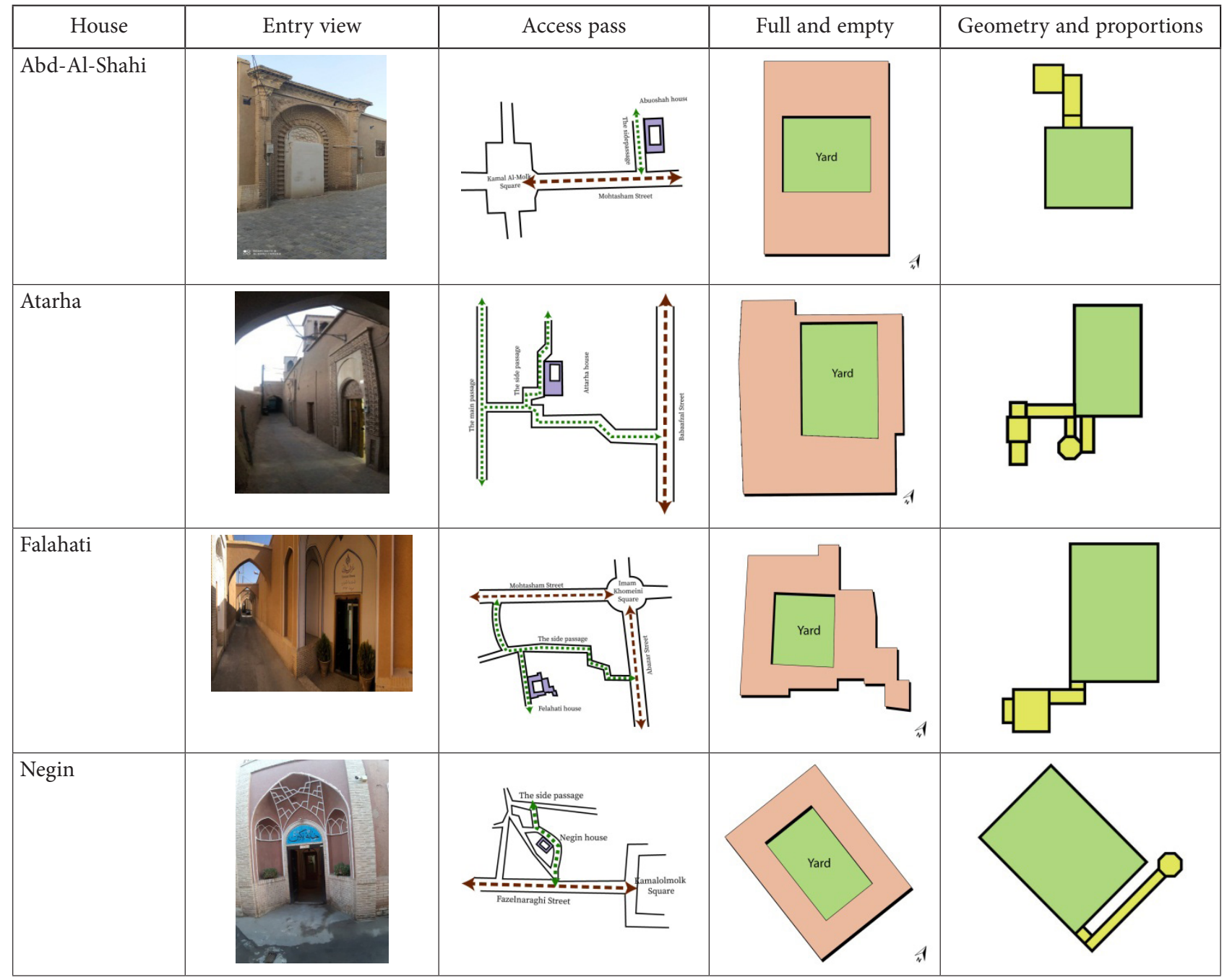

Figure 5. Location of houses in the passage, volume and geometry of houses in case studies

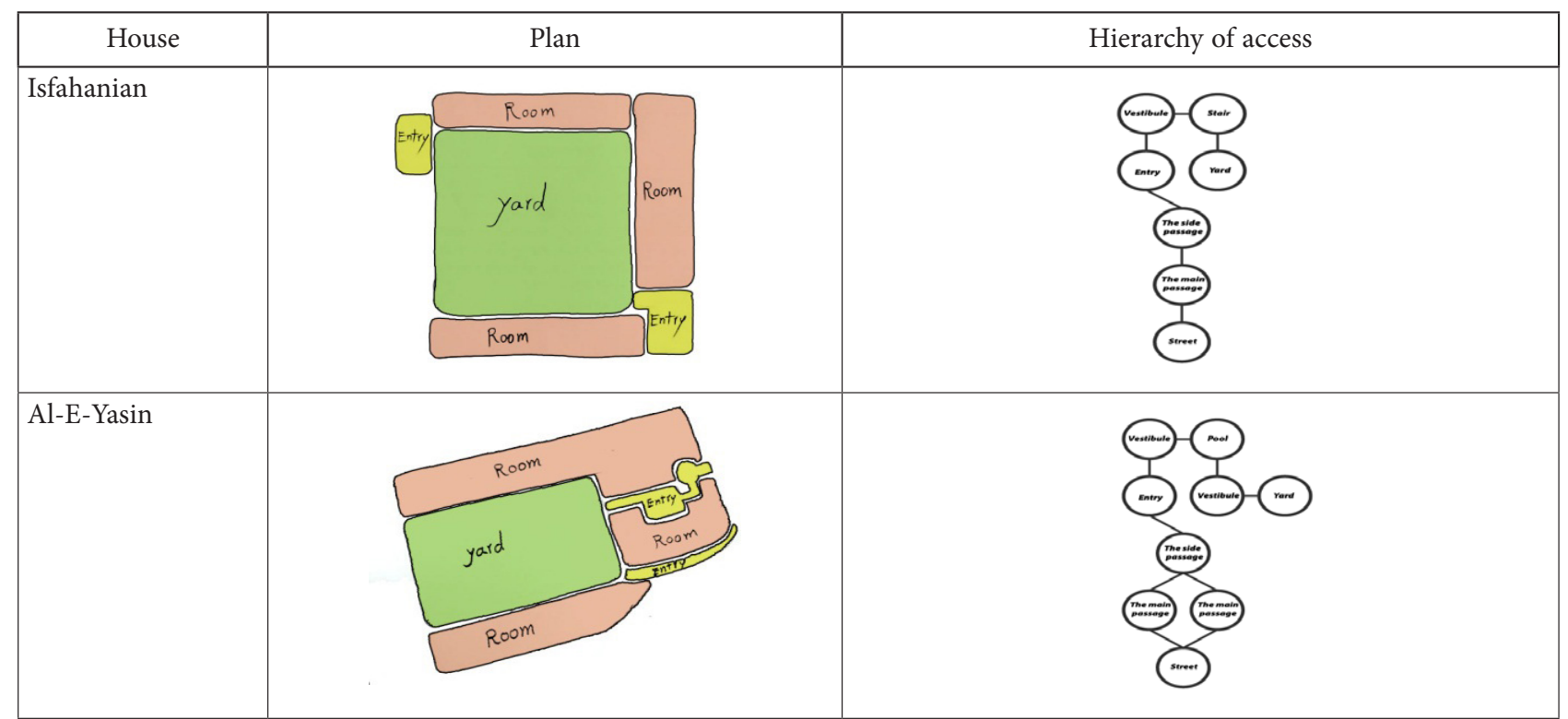




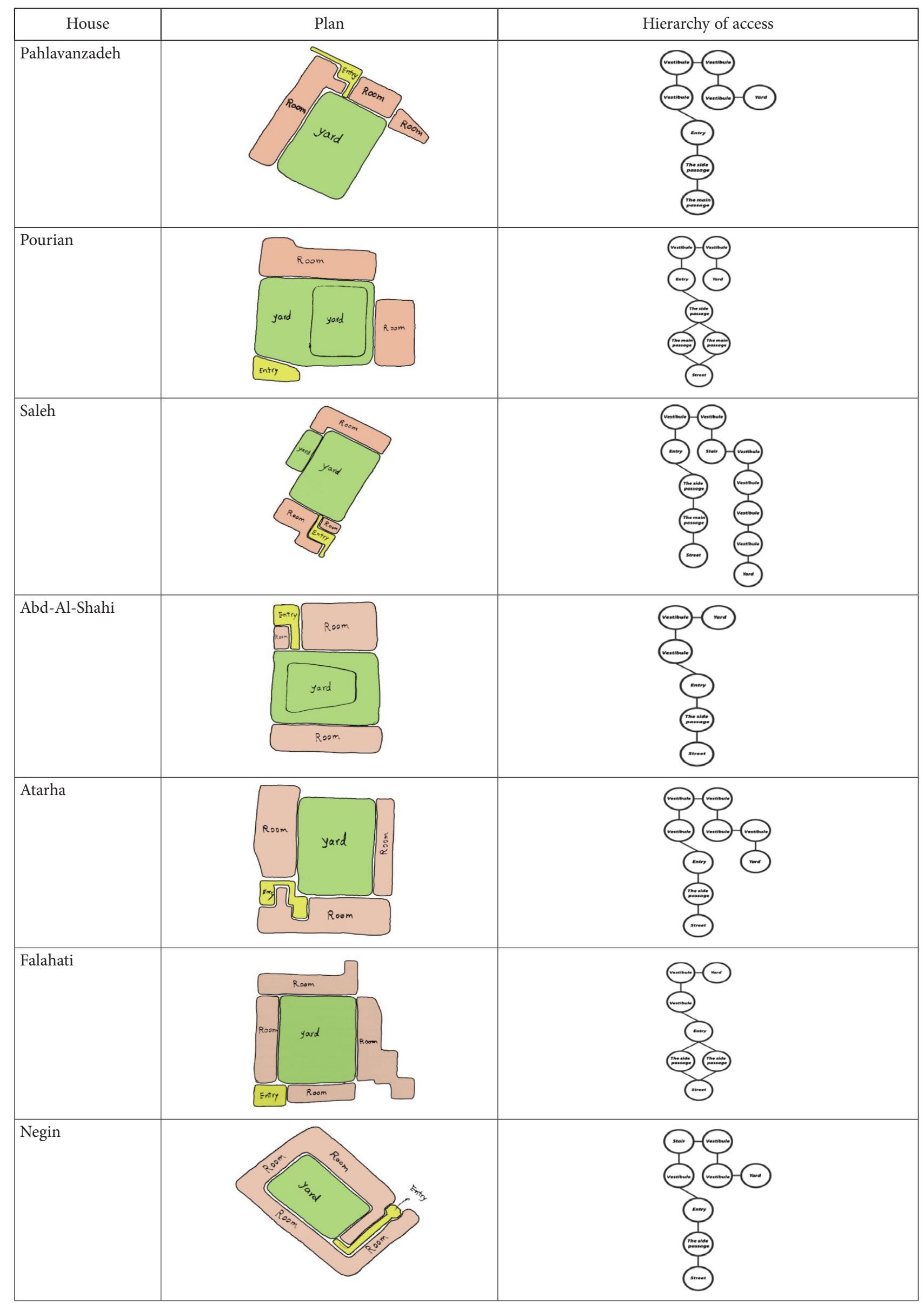

Figure 6. Position of entrance in different buildings in case studies 
Input is effective in the process of perceiving the environment and explaining the character of the place and it is known as a semantic factor in understanding the concept of residence.

The entrance value and their functions are so high that the geometry and spatial relationships of the interior components of the house are based on the input position (Figure 6).

In Table 2, based on the Depth map software, analyzes the integration characteristics, radius of vision, and visual depth (intimacy) that were examined and emphasized in the background, through the software ${ }^{1}$. Connecting as a criterion for assessing the coherence of a place is effective in strengthening the sense of belonging to the place through the diversity of passages and impasse and the extent to which the entrance communicates with them. Accordingly, a space that has a high degree of coherence also has a higher degree of Integration, and in that place, there is a greater variety of activities. Analysis of this index in case studies, with an average of 4.7 , indicates a relatively high degree of this index.

The radius of vision is another topic that has been analyzed to assess the role of entrance in increasing the sense of promotion of dependence to a place.
In fact, when the landlord opens the door to the client, he should be able to have initial control. This feature, which is an important behavioral and functional pattern in the historical neighborhoods of Kashan, has examined the radius of vision in the initial event, in the time of opening. This component can be introduced as a criterion for evaluating safe areas in the neighborhood. This means that the red areas have the most visibility from the surrounding passages. Based on this feature, the average viewing radius in the studied samples is 52.3 degrees. It shows that a good connection has been established between the house and the neighborhood, and locations of entrances have played a role in this connection.

Visual depth is the third characteristic that is effective in strengthening the sense of belonging to a place and is defined as a criterion for assessing privacy in a range. Depth of view is directly related to the subject of location dominance. In fact, it is the feeling of security that is created through the radius of access, is completed by dominating the alley where the house is located, and through this, a collective security is formed and a meaningful neighborhood is created. In other words, a space that has high visual depth has a high privacy. The software evaluation for this indicator shows an average of 2.9 and shows the high privacy of the entrances and strengthens the sense of belonging to the place in them (Table 2).

Table 2. Critical field analysis on connectivity, radius of vision and visual depth in case studies (Author, 2020)

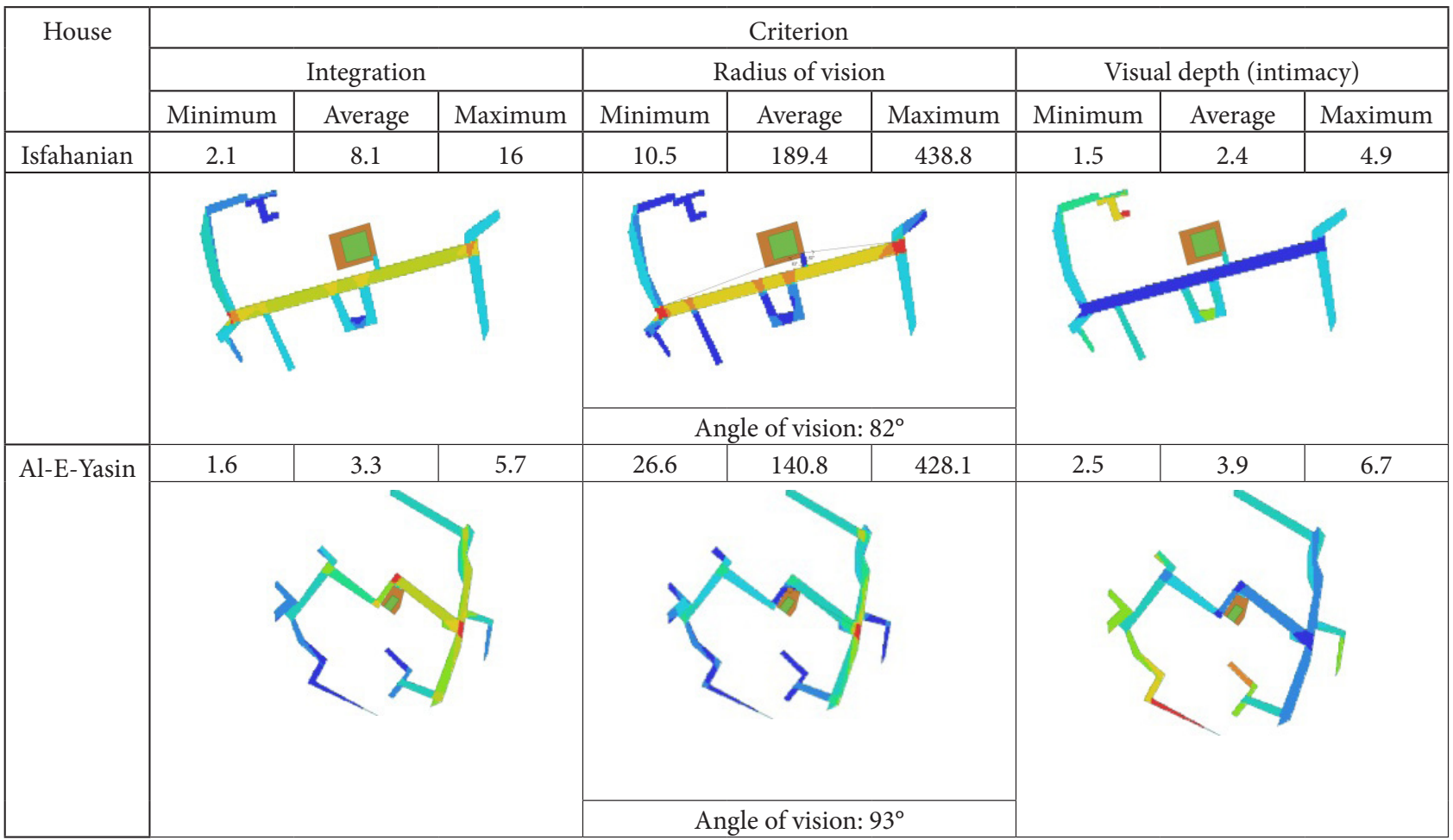

\footnotetext{
1 In the analysis, the warm color (red here) means an increase in the numerical value of the criterion and the cold color (here in blue) indicates a decrease in the numerical value of that criterion.
} 
Continue of Table 2

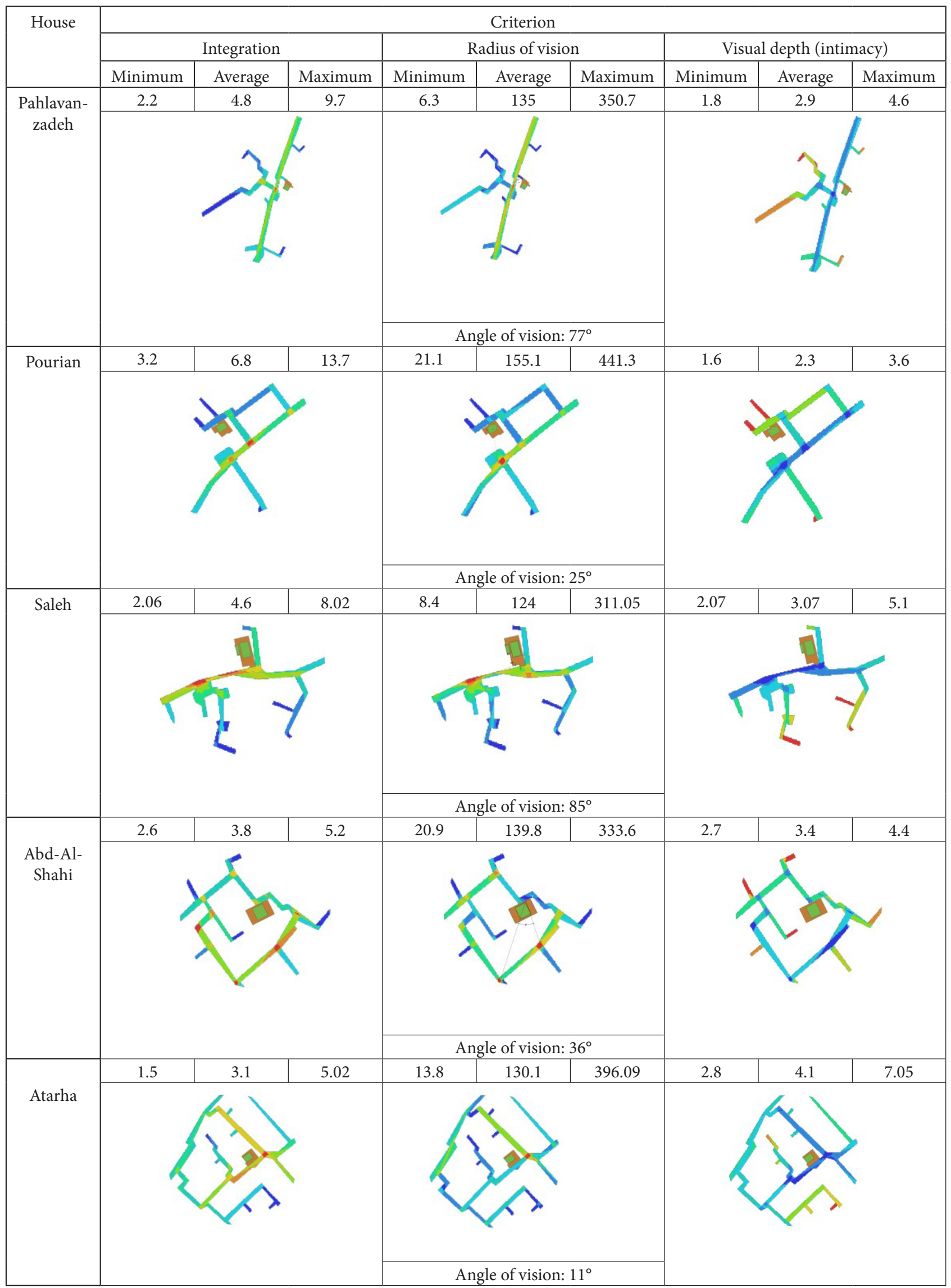


End of Table 2

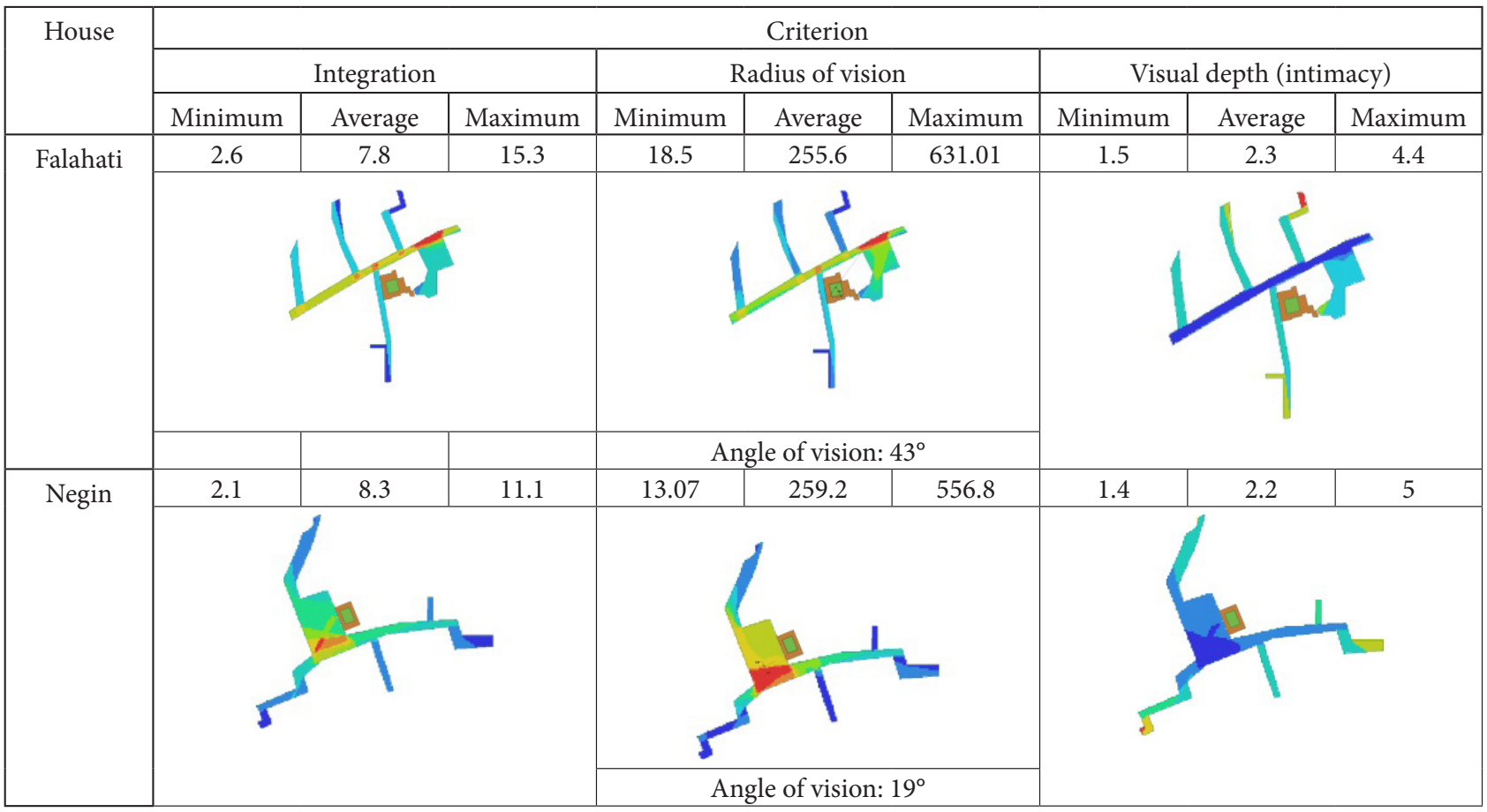

\section{Conclusions}

The entrance of Kashan houses shows the type and extent of people's interaction with each other and has an important role in the mental imagery of the inner space. Audiences communicate with the home through the entrance space. Therefore, the semantic function of the entrance is as important as its functional performance and it is very effective in enriching the sense of belonging to the place. The most important functions of the entrance space of Kashan's historical houses can be classified as follows:

1. Entrance as a qualitative element

Quality is how a thing or phenomenon is, and it distinguishes between phenomena and it can be the result of the form (formal qualities), performance (functional quality), or semantic one thing (semantic quality). As much as human beings belong to space, the higher the qualitative values of that space.

This requires that space be more human-centered and easier to interact with the environment; Meet human needs and be a good container for behavioral patterns.

2. Determinant of territory

The historical houses of Kashan have a wide territory due to the deep relations between people and their interactions. Thus, a house is not only defined by its physical space but the relationships between houses, public, and social spaces and passages, form the concept of houses. Accordingly, there is certain integration between the houses.

3. Increase the sense of belonging to the place

The control and supervision that takes place due to the location and design of the entrance space is an important factor in creating or strengthening the sense of belonging to the place.

4. Increase security and performance monitoring

The connection between an enclosed space and the surrounding environment must be subject to multiple functional and social considerations and in the first place, one must pay attention to the functional characteristics of a building, especially the hierarchy of its social function.

The entrance station, as the first place where the general characteristics of the space are discovered, plays a role in creating a sense of interest and constant presence in the space and this interest is due to the spatial integrity, the right radius of vision and the depth of vision that is made possible by good design and convenient entry position. In this way, these characteristics cause attention, learning, memory, conceptualization, and meaningfulness, which the audience understands better and deeper through the formation of cognitive maps and mental imagery and the proper functioning of the entrance space.

\section{Acknowledgments}

Special thanks are due to Seyyed Mohammad Hosseini, who has helped the author to perform software analysis.

\section{References}

Alexander, C., Ishikawa, S., \& Murray Silverstein, M. (1977). A pattern language: towns, buildings, construction. Oxford University Press.

Altman, I., \& Low, S. M. (1992). Place attachment (3th ed). Academic Press. https://doi.org/10.1007/978-1-4684-8753-4 
Brown, G., \& Raymond, C. (2007). The relationship between place attachment and landscape values: toward mapping place attachment. Applied Geography, 27(2), 89-111. https://doi.org/10.1016/j.apgeog.2006.11.002

Bourdieu, P. (1977). Outline of theory of practice. Cambridge University Press. https://doi.org/10.1017/CBO9780511812507

Breakwell, G. M. (1992). Processes of self-evaluation: efficacy and estrangement. In G. M. Breakwell (Ed.), Social psychology of identity and the self. Surrey University Press in association with Academic Press.

Canter, D. (1971). The psychology of place. The Architectural Press.

Di Masso, A., Dixon, J., \& Durrheim, K. (2014). Place attachment as a discursive practice. In L. Manzo, \& P. D. Wright (Eds.), Place attachment: advances in theory, methods and applications (pp. 75-86). Routledge.

Falahat, M. S., \& Noohi, S. (2012). The nature of signs and their role in enhancement of sense of place in architectural spaces. Honar-Ha-Ye-Ziba, 17(1), 17-26.

Ghahari, A. R (2015, July). Iran's architecture prideworthies fundation. http://www.ammi.ir

Hammitt, W. E., Backlund, E. A., \& Bixler, R. D. (2004). Experience use history, place bonding, and resource substitution of trout anglers during recreation engagements. Journal of Leisure Research, 36(3), 356-378. https://doi.org/10.1080/00222216.2004.11950028

Hashemzadeh, H., Heydari, A. A., \& Mohammadhoseini, P. (2013). Sense of place and place attachment. Architecture and Urban Development, 3(1), 5-12.

Hidalgo, M. C., \& Hernandez, B. (2001). Place attachment: conceptual and empirical. Journal of Environmental, 21(3), 273281. https://doi.org/10.1006/jevp.2001.0221

Jorgensen, B. S., \& Stedman, R. C. (2006). A comparative predictors of sense of place dimension: Attachment to dependence on, and identification with lakeshore properties. Environment Management, 79(3), 316-327.

https://doi.org/10.1016/j.jenvman.2005.08.003

Jorgensen, B. S., \& Stedman, R. C. (2001). Sense of Place as an attitude: lakeshore owner's attitudes toward their properties. Environmental Psychology, 21(3), 233-248. https://doi.org/10.1006/jevp.2001.0226

Kyle, G., Graefe, A., \& Manning, R. (2005). Testing the dimensionality of place attachment in recreational settings. Environment and Behavior, 37(2), 153-177. https://doi.org/10.1177/0013916504269654

Lewicka, M. (2011). Place attachment: how far have we come in the last 40 years? Environment Psychology, 31(3), 207-230. https://doi.org/10.1016/j.jenvp.2010.10.001

Mehdipoor, H., Jafari, R., \& Sadati, S. P. (2013). The role of "Jelo khan" in residential vernacular architecture of Iran. Housing and Rural Environment, 32(142), 3-18. http://jhre.ir/article1-241-en.html

Messy, D. (1994). Space, place and gender. University of Minnesota Press.
Mozaffaripour, N. (2014). Recognizing effective factors in entrance scape of commercial and religious buildings to improve sense of invitation (Case study: Tajrish Area, Tehran). Urban Landscape Research, 1(1), 17-24.

Norberg-Schulz, C. (1981). Genius Loci: paysage, ambiance, architecture. Mardaga.

Norouzitalab, A. (2006). The text originality as the antecedent of criticism and interpretation. Bagh-e Nazar, 3(6), 100-111.

Parkinson, J. R. (2000). Democracy and public space: the physical sites of democratic performance (1st ed.). Oxford University Press.

Proshansky, H. M. (1978). The city and self-identify. Environment and Behavior, 10(2), 147-169. https://doi.org/10.1177/0013916578102002

Rapoport, A. (1990). The meaning of the built environment: a nonverbal communication approach. University of Arizona Press.

Raymond, C. M., Kytta, M., \& Stedman, R. (2017). Sense of place, fast and slow: the potential contributions of affordance theory to sense of place. Frontiers in Psychology, 8, 1-14. https://doi.org/10.3389/fpsyg.2017.01674

Relph, E. (2008). Disclosing the ontological depth of place: Heidegger's topology by Jeff maps. Environment and Architectural Phenomenology, 22(4), 4-16.

Relph, E. (2009). A pragmatic sense of place. Environmental and Architectural Phenomenology, 20(3), 8-19.

Relph, E. (1976). Place and placelessness. Pion and Sussex Academic Press.

Scannell, L., \& Gifford, R. (2010). Defining place attachment: A tripartite organizing framework. Journal of Environmental Psychology, 30, 1-10. https://doi.org/10.1016/j.jenvp.2009.09.006

Shamai, S. (1991). Sense of place: an empirical measurement. Geuforum, 22(3), 347-358. https://doi.org/10.1016/0016-7185(91)90017-K

Stokols, D., \& Shumaker, S. A. (1981). People in places: a transactional view of settings. In J. H. Harvey (Ed.), Cognition, social behavior, and the environment (pp. 441-488). Lawrence Erlbaum Associates.

Sultanzadeh, H. (1993). Urban spaces in historical fabrics of Iran. Cultural Research Office in Corporation with Tehran Municipality.

Tavassoli, M. (2008). Urban design, the art of renewing urban structure, with four case studies. Khane-ye Chap and Tarh.

Twigger-Ross, C. L., \& Uzzell, D. (1996). Place and identity processes. Environmental Psychology, 16(3), 205-220. https://doi.org/10.1006/jevp.1996.0017

Wagenaar, H. (2011). Meaning in action: interpretation and dialogue in policy analysis. M.E. Sharpe.

White, D. D., Virden, R. J., \& van Riper, C. J. (2008). Effects of place identity, place dependence, and experience-use history on perceptions of recreation impacts in a natural setting. Environmental Management, 42, 647-657. https://doi.org/10.1007/s00267-008-9143-1 